The knock-on effects of green buildings: High-rise construction design implications

\begin{tabular}{|r|l|}
\hline Journal: & International Journal of Structural Integrity \\
\hline Manuscript ID & IJSI-06-2021-0062.R1 \\
\hline Manuscript Type: & Research Paper \\
\hline Keywords: & $\begin{array}{l}\text { Embodied Energy, LEED, Demolition energy, Life span of the building, } \\
\text { Life span of the materials }\end{array}$ \\
\hline \multicolumn{2}{|l}{} \\
\hline
\end{tabular}

SCHOLARONE ${ }^{\text {mW }}$

Manuscripts 


\section{Dear Prof. Shun-Peng Zhu}

Thank you for reviewing our paper. We would like to also thank both of the reviewers for the important and valuable comments and suggestions. As you will notice, we have carefully incorporated their comments into our document, and thus considerably revised it. Thus, please note that there has not been any rebuttal on any of the points raised. We have highlighted (in yellow) the revised sections throughout the paper. We provide the following responses to the reviewers' comments:

\begin{tabular}{|l|}
\hline Reviewers comments \\
\hline Editor:
\end{tabular}

In introduction, more recent progress should be strengthened. P.s. you may wish to consider citing some recent relevant papers published in the IJSI by your peers. For your convenience, I have attached the Table of contents of papers published in the IJSI in the past couple of years.

\section{Reviewer 1:}

This paper deals with the green buildings concept in high-rise constructions, which is significantly important in coping with climate changes recently. Green building is a very big subject that involves a lot, but this manuscript is wellorganized and describes this concept clearly. The literature review section does provide a comprehensive understanding of green buildings in a comprehensible way, and in the following parts of this paper, some in-depth discussions have been made. I consider this paper is adequate to be published in IJSI except for one minor question: In page 12 , Line 24 , is the number 3.2 missing?

\section{Reviewer 2:}

1- the abstract needs to be summarised the main points and avoid unnecessary parts to understand better and readability.
We would like to thank you for the list of suggested papers. From that list we have found 2 papers which closely align with our research. While Kheradmand et al., (2019) provide interesting investigation of green spaces particularly how to better plan for green infrastructure, Huijun et al., (2020) specify future analysis of improved concrete durability which ultimately could sustainability implications for the high-rise construction design. We have therefore substantiated some of the arguments made within our manuscript with the additional citations.

Thank you. We have now rectified this: 3.2 Selection of research approach/method.

Thank you. This is now completed. Please also see our point by point responses below:

1. We have now completely rewritten the abstract section.

2. Within the findings section, we have included the most critical quantitative result. 
The abstract is very general, with unnecessary statements. Please revise the abstract. 2- Please underscore the scientific value added in the abstract. Add some of the most critical quantitative results to the Abstract.

3- Keywords must indicate the primary materials, tests, and methodology used in the study. However, it is required to revise the keywords and write based on the points mentioned above. 4- - The discussion is concise and not in detail. Improve it with logic statements.

5- The conclusions need to be revised and improved. Please make sure the conclusion section underscores the scientific value added to the paper and the applicability of the findings/results. The conclusions are very general, with unnecessary statements. 6- A big number of not recent references is discussed in the Introduction; therefore, this section should be updated. The review of existing literature should be more critical

7- The Reference list should be updated.

8 - Please revise figure $2 b$ and enhance the quality. 9- $\quad$ Please revise figure 6 and enhance the quality.

Please let us know, if you have any questions. Thank you.
3. The keywords are now revised to represent the requested changes. We have revised the list of keywords to reflect the methodology of the study more appropriately.

4. The introduction section has been rewritten completely to be more logical and precise. Further, some of the sections of the literature review section have also been rewritten for this purpose. 5. Please note that we have rewritten the conclusion section to better underscore the values added for the high-rise design and construction practices.

6. Please note that we have now added more recent and specific references throughout this paper.

7. We have included a total of 11 most recent and relevant references. Please see the reference list which includes the new additions highlighted.

8. Figures $2 b$ has been enhanced to improve its readability and quality.

9. Figures 6 has been enhanced to also improve its readability. 


\title{
The knock-on effects of green buildings: High-rise construction design implications
}

\begin{abstract}
Purpose - The aims and objectives of this research are to establish whether or not the transition into green building in high-rise construction is practical. This is after considering several perspectives including financial, economic, environmental, social. This subsequently leads to an evaluation on whether or not the continuation with a standard conventional build of high-rise buildings remains to be the most feasible option. Such objectives, therefore, aim to allow for validation of how and why high-rise construction designs are impacted through green buildings effects.

Design/methodology/approach - Through six defined steps, the methodology commences with an introductory section of what it means to build green. This section is further broken down to evaluate what factors are involved in constructing a green building. Furthermore, the Life Cycle Energy (LCE) is used as a framework to evaluate the knock-on effects of green buildings and subsequent high-rise construction design implications.

Findings - Through defining the ongoing relationship of green materials and sustainable design, various implications for high-rise constructions were discovered. First and foremost, it was determined that the LCE is the central consideration for any high-rise building design. In evaluating the LCE, and overall operating energy of the 50 -year cycle of a building was carried out. As the results showed, the operating energy represents around $85 \%$ of the total energy that is consumed at the end of the 50 year cycle of the building. Precise LCE calculation can lead to a more efficient design for high-rise buildings. As a result, an increased understanding of the current status of green buildings within the construction industry is paramount. This understanding leads to a better insight into the contributing factors to green building in high-rise construction and the construction industry in general.

Originality/value - The potential contribution that can be gained from this research is the awareness that is raised in the research and development of green buildings in high-rise construction. This can be achieved by using certain materials such as new energy-efficient building materials, recycled materials, and so on. This research will contribute to defining a new way of sustainable buildings, particularly for high-rise construction. The outcome of the research will be beneficial for practitioners such as design engineers and other related professions.
\end{abstract}

Paper Type - Research paper

Keywords: Embodied Energy, LCE, LEED, Demolition energy, Life span of the building, Life span of the materials.
Abbreviations and notations
$\mathrm{EE}_{\mathrm{i}}=$ Initial Embodied Energy of the building
$\mathrm{EE}_{\mathrm{r}}=$ Recurring embodied energy of the building
$\mathrm{m}_{\mathrm{i}}=$ Quality of the Building Material
$\mathrm{M}_{\mathrm{i}}=$ Energy Content of Material per unit
$E_{c}=$ Energy used at site for erection/ construction of building
$\mathrm{L}_{\mathrm{b}}=$ Life span of the building
$\mathrm{L}_{\mathrm{m}}=$ Life span of the materials
$\mathrm{OE}=$ Operating energy in the life span of the building 
$\mathrm{E}_{\mathrm{OA}}=$ Annual operating energy

$\mathrm{DE}=$ Demolition energy

$\mathrm{E}_{\mathrm{d}}=$ Energy Incurred for destruction of the materials

$\mathrm{E}_{\mathrm{r}}=$ Energy used for transporting waste materials

$\mathrm{LCE}=$ Life Cycle Energy

\subsection{Introduction}

The construction industry is continuously evolving to keep up with sustainability standards and expectations. These developments commonly see a lasting effect on the way buildings are designed, built, and maintained (Gharehbaghi et al., 2021a). One of the most recent developments introduced into the construction industry is for green buildings, particularly for high-rise constructions. As highlighted by Sim (2019), the green building aims to alter the built environment by making more of an allowance for energy efficiency design. This ultimately will produce efficient building design practices which in turn, benefit the built environment field (Dimitriou et al., 2020). To support this outcome, specific bodies such as the U.S. Green Building Council were initially formed (Kumari et al., 2020). Furthermore, Kubba (2016) argued that the Leadership in Energy and Environmental Design (LEED) foundation was carefully developed, with the primary aim of providing a mechanism to measure green buildings and the rate of their efficiency. LEED includes sustainability elements such as site impacts, energy and water use, materials and resource conservation, and indoor environmental quality.

Importantly, on many occasions, the green building methodology has been shown to reduce Carbon Dioxide emissions by approximately $40 \%$. The research conducted by Gharehbaghi et al. (2021) indicated that green building methodology could significantly assist with the high-rise design. However, Armstrong (2015) noted that the main issues that surround the green building in high-rise construction come from the willingness of both the client and the builder to make the transition from a standard traditional build to a green build. Subsequently, the main issue surrounding the process of transitioning from conventional construction to green construction is regardless of the positive findings toward building green; but rather the willingness to implement the required design changes (Kheraadmand et al., 2019). Authors such as Lotfy and Al-Fayez (2015) and Maduabuchukwu et al. (2020) among others, strongly argued the need for innovative thinking to improve better design practices for high-rise buildings. Typically, the issues of building green can arise within any phase of construction whether it be the design phase or the building phase. This encompasses, the materials selection and the possible costs incurred by using green materials, leading to the issue of finances in green buildings.

This research addresses such problems by dissecting all issues surrounding the transition and critically evaluating the negatives and the outcomes they will evoke, as well as their lasting effects. Through reviewing the knock-on effects of green buildings, this research will promote both builders and clients to look in-depth at the possible opportunities for high-rise construction. Comparing the conventional construction vs. the green methodology, various design implications will be investigated. The research provides evidence for the claims made in support of the transition into green building for high-rise construction.

The rest of the paper is structured as follows; Section 2. Provides a detailed review of literature, and 
highlights the background of the study. The adopted methodology is presented in section 3 . Section 4 outlines the results of our work and the related discussions. The paper is concluded in Section 5.

\subsection{Literature review and background}

As already noted, the construction industry is constantly progressing to keep pace with ongoing sustainability standards and intentions. Materials selection and use are one of the central domains of ongoing sustainability rapprochement (Gharehbaghi, 2015; Arığlu et al., 2017). In their extensive research, Hirvonen et al. (2019) put forward the concept of increased recycled materials with a more efficient building design. Earlier research such as Xua et al. (2012) and Yan et al. (2017) among many, also alluded to such outcomes, particularly for high--rise construction. Further, the United Nations Environment Program (2018) reviewed that, the selection of the materials in green building such as recycled materials, can be used to assist the transition to making high-rise construction design more efficient.

Moreover, the new materials being introduced into high-rise construction are also making the construction more efficient as opposed to preceding construction projects that have taken place (Jaillon and Poon, 2008; De Luca et al., 2021). Studies have given an insight into the rating systems each of these possible changes on sight can assist in the environmental design and construction, and have also been able to create awareness into the possible financial and economic benefits surrounding this type of high-rise construction (Huijun et al., 2020). The overall benefits and limitations are also discussed throughout the paper, as they form a large part of the research and development into defining the worth of the green building in high-rise construction projects. Research in this area has revealed that there is a basic level of understanding surrounding the benefits that may be reaped if a transition to the green building was made. The level of ignorance in this field has proven to be a large contributor to the effects on the environment from the construction industry (Zhang and Canning, 2011; Gharehbaghi, 2017; Chew and Conejos, 2017; Eckelman et al., 2018).

The important question for those operating in the construction industry to remember is the material transitions from standard to green can benefit the overall project profit margin by reducing costs, and by maximizing both economic and environmental performance (Chew, 2016). However, some green building materials may cause an increase to the initial project cost, which does not seem to reap any benefit in the beginning during construction but will have some benefit throughout the operation of the actual building this is discussed further below. In future construction projects, it should be encouraged from the design team for the builders and superintendents to encourage a green building process to be implemented for the construction phase, thus gradually introducing the process of building green and allowing all individuals of the construction industry to become familiar with the heightened level of beneficial outcomes (Conejos et al., 2019).

\subsection{Background information}

One of the key developments, within the construction industry through time is to slowly implement different aspects of green building into each project. According to Cidell (2009), one of the most important attempts to reduce the environmental impacts of the built environment is through the construction of green buildings. This notion was also supported by Gharehbaghi et al. (2021) research were extensive evaluation 
of sustainable building design (SBD) of various buildings were undertaken. Nonetheless, the statement by Cidell (2009) validates the points raised earlier regarding the reason why making a transition into the green building in high-rise construction is so important. As explained by Bovea and Powell (2016) as well as Estanqueiro et al. (2018), green buildings can be simplified down to those buildings that use key resources like energy, water, materials, and land more efficiently than those buildings that are built to code. The buildings that consume less energy are those of which that have been designed specifically to demand less energy as opposed to that of a conventional build.

It is clear that in previous years, the importance of creating an environmental design and building green did not hold as much importance as it does today (Densley and Davison, 2012; Chew et al., 2017; Gharehbaghi et al., 2020b). The push for the transition into building green was never enforced as it was most commonly viewed as an impracticable option to take part in for the business world, therefore before the build taking place the actual designs were not being created accordingly thus leaving the concept of building green as just that, a concept (Chua et al., 2018; Guerra et al., 2019; Gharehbaghi et al., 2020a). Coming into recent times research has since been developed and highly promoted, there has been an emphasis put on making a transition from standard building to green building for high-rise construction where the energy consumption during the construction phase is reportedly at a record-breaking high. By implementing this transition there is the opportunity to make an immense difference on all surrounding environmental factors. As stated by Ilhan and Yaman (2016) there are several surrounding factors as to why the transition into the green building has made its debut. These reasons are:

- There has been a recent introduction into reliable building ratings and performance measurement systems.

- The financial benefits have been proven to be true when putting in place a well-designed green building.

- Green building materials are becoming more and more accessible as time goes on.

Whilst most people refer to green building as only being of benefit to the environment, more and more studies such as Jones (2019) are proving that the benefits are touching base with all areas. These benefits are more noticeable in the high-rise construction projects where aspects such as green materials are moreand-more being adopted. Systematically, the principle of green materials can range from recyclability and re-use to support sustainable building principles (Pacheco-Torgal et al., 2013). The relationship between green materials and sustainable buildings is shown in Figure 1. 


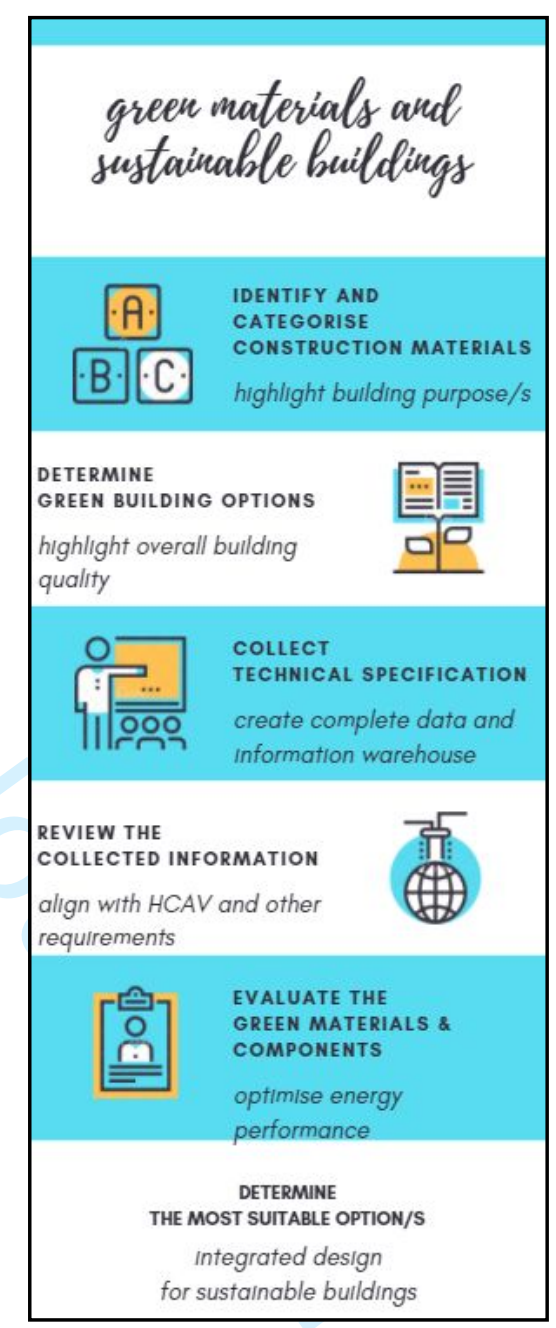

Figure 1: The relationship of green materials and sustainable buildings (source: authors).

As shown in Figure 1, the relationship between green materials and sustainable buildings consists of 6 primary stages. Ranging from identifying and categorize construction materials to determine the most suitable option/s are the most systematic processes to promote sustainable buildings. One of the key aspects of this relationship is the inclusion of optimizing energy performance. This could include the use of recycled materials. Interestingly, the introduction to the use of recycled materials in high-rise construction buildings has only just become more common throughout the construction industry (Hossain et al., 2016; Gharehbaghi and Rahmani, 2018; Hadavand and Imaninasab, 2019). The use of recycled materials is proven to have a better outcome for those occupying the building after construction, as opposed to the classic building materials used (Iacovidou and Purnell, 2016; Climate Policy Initiative (CPI), 2017). How the building is built holds just as much importance within the environment, as where and what is built. According to Hahladakis et al. (2020) and Maduabuchukwu et al. (2020), the definition of Recycled Content is the portion, by mass of pre--consumer or post-consumer recycled material within a product. This definition is important to remember, as the whole amount of building material may not be recycled, it may just be partially made up of recycled goods. Some recycled materials that are common amongst the construction industry are:

- Metals (Steel \& Aluminum): When looking at products that have the potential to be recycled one of the most commonly referred to products is, metal in the form of Steel and Aluminum. Metals have a high potential for recycling, and it is becoming a common thread amongst a lot 
of construction projects that metal products used in the application have a significant amount of recycled content. Metal products provide high strength and excessive durability (Lukman et al., 2019; Gharehbaghi et al., 2021b). Structural Steel production has an incorporation of recycled steel products for the manufacturing of new steel. There is an estimate of $32 \%$ of recycled content. The recycling of aluminum shows some environmental benefits, such as the fact that it only requires 5\% of the energy needed to produce aluminum, which consequently eliminates $95 \%$ of greenhouse gasses that would normally be associated with the generation of aluminum manufacturing.

- Concrete: The process of recycling concrete is simpler than is originally anticipated. The process involves the removal and crushing of existing concrete into a specified size. Figures $2 \mathrm{a}$ and $2 \mathrm{~b}$ show the process of the concrete recycling system and method.

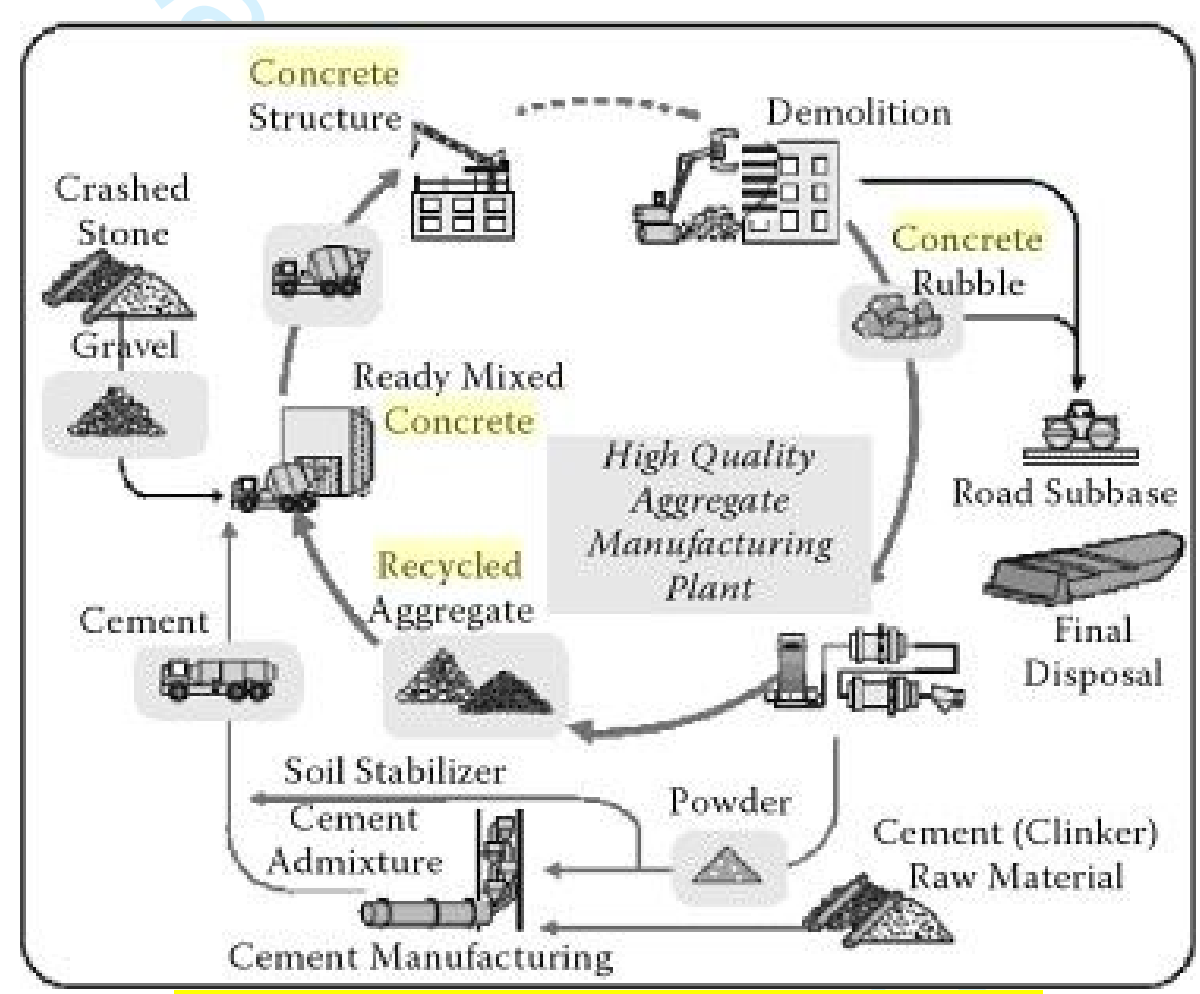

Figure 2a: Concrete Recycling System (Hirokazu et al., 2005). 


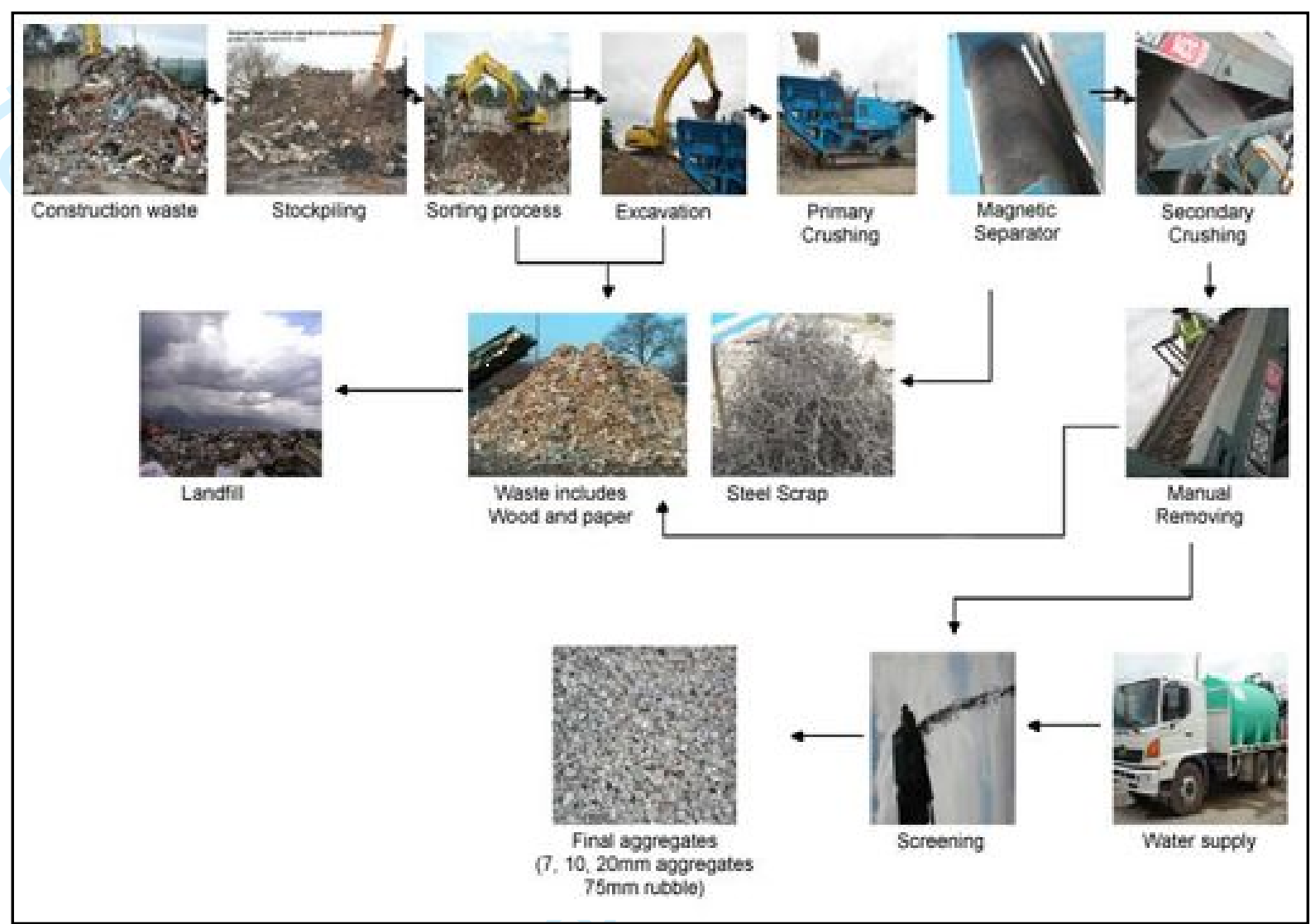

Figure 2b: Flow chart of the current recycling method (modified by Arora, 2015).

The typical mix used for concrete is between $12-15 \%$ of cement and $75-80 \%$ of aggregate by mass, (sand, gravel, crushed rock). The recycled component in concrete is usually the aggregate, which can be mixed with the cement to make new concrete. Further, Mohammed et al., (2015), found that the quality of the concrete relies on the quality of the recycled materials that are used.

- Plastic: Within the construction industry one of the most fundamental components of used building products, is plastic (Ollila, 2012; Gharehbaghi and Chenery, 2017). This is including both virgin and recycled plastic.

Furthermore, Lieblang (2014) as well as Lockrey et al. (2018), explain in their book how green building materials are nontoxic, and most commonly made of recycled materials as discussed above. These materials are energy efficient, how they are manufactured introduces them to be a 'green material' but the way they are used and then reclaimed after their initial use is how they maintain their name as a green building material. The main principles that need to be considered whilst building green in high-rise construction is, to reduce the resource consumption, reuse any possible resources, use recyclable resources where possible, protect the surrounding nature, eliminate toxins, apply a life cycle costing where possible in regards to the economics, and put a significant focus on the quality being produced in all aspects of the construction (Pacheco-Torgal and Jalali, 2011; Gharehbaghi et al., 2018).

When considering whether to build green or not the decision is always narrowed down to the cost. Although the capital involved in the construction of a green high-rise building may be more, the energy-conserving systems implemented will shortly recoup their original investment within a short time. The building 
materials often cost more than the materials they are in turn replacing, for example, compressed weatherboard, which is a common replacement for plywood, can cost up to 4 times the amount. According to Iacovidou et al. (2017), it is important when focusing on the financial benefits expected through green building, not to expect these benefits to show in the construction profit margin, but more so in the building operation costs, as these lowered costs are associated with lower energy consumption, water consumption, recyclability of wastes, environmental and emission costs and increased productivity and health of those occupying the building.

In the United States the U.S. Green Building Council (2000), has developed the LEED foundation, which is a set of rating systems for a particular design or construction of green buildings. The main intention of LEED is to assist in being environmentally responsible by efficiently using resources for construction. According to the U.S. Green Building Council LEED (2015) is helping the industry "transform the way they think about how buildings and communities are designed, constructed and maintained and operated across the globe". The LEED organization is globally recognized as a mark of achievement and a step forward in green building.

\subsection{Previous research analysis: High-rise construction design considerations}

The evaluation of building green in high-rise construction has discovered many benefits involving environmental and economic aspects (Kubba, 2016). The level of ignorance that may be experienced when discussing the possibility of building green may overshadow this (Armstrong, 2015). This unfamiliarity may be because a majority of informative articles mainly focus on the factors discussed earlier such as environmental and economic involvement as seen in Mirrahimi et al. (2016) and Raji et al. (2015). In their research, Charalambides et al. (2019) reminded that issues surrounding the construction industry are most likely than none always involving the environmental and financial aspects, rather than focusing on the sustainability aspects. This notion was also supported by Braga et al. (2017) who explored the sustainability needs and concerns surrounding building green in high-rise construction. Such articles detail the importance of all aspects required to be considered when focusing on green buildings in high-rise construction.

Enshassi et al. (2018), Krueger et al. (2019), and Singh et al. (2015) identified the common thread throughout the construction industry, which is the raised issue of the effect that the full construction process is having on the environment. The articles identify the fact that this issue has been identified by many involved in the construction industry, it also offers an insight into the possible conflict of interest between building from a financial point of view, where costs are kept to a minimum by the client, or building with a more conscious view of the environment concerning the air quality, comfort levels, and health and safety issues. The discussion opens up about introducing an Environmental Building Assessment, to be able to satisfy the requirements of all parties involved. The performance of a building has evolved to be one of the most concerning factors in this time for the construction industry, where an evaluation of the environmental performance over the life of the building is made (Akadiri, 2015; Eriksson et al., 2019; Peng et al., 2019). The purpose of this development is to focus on how successful or unsuccessful a certain high-rise construction project has been with regards to being able to balance energy, environmental sustainability, and incorporating the financial requirements concurrently. The point raised in this article is that when constructing a high-rise building, and wanting to incorporate elements of the environmental assessment if 
these tools are introduced at the design stage there is a good chance that it can minimize the environmental damages that may be caused by construction. The most rewarding benefit of any construction project is the financial return that can be achieved. The point raised in this article stating that even though a project may be environmentally sound, it may not maintain cost-effectiveness and therefore the initial aim of construction which is financial benefit will not be fulfilled. Nonetheless, building green has many implications specifically for high-rise constructions. Figure 3 displays the green building's implications for high-rise constructions.

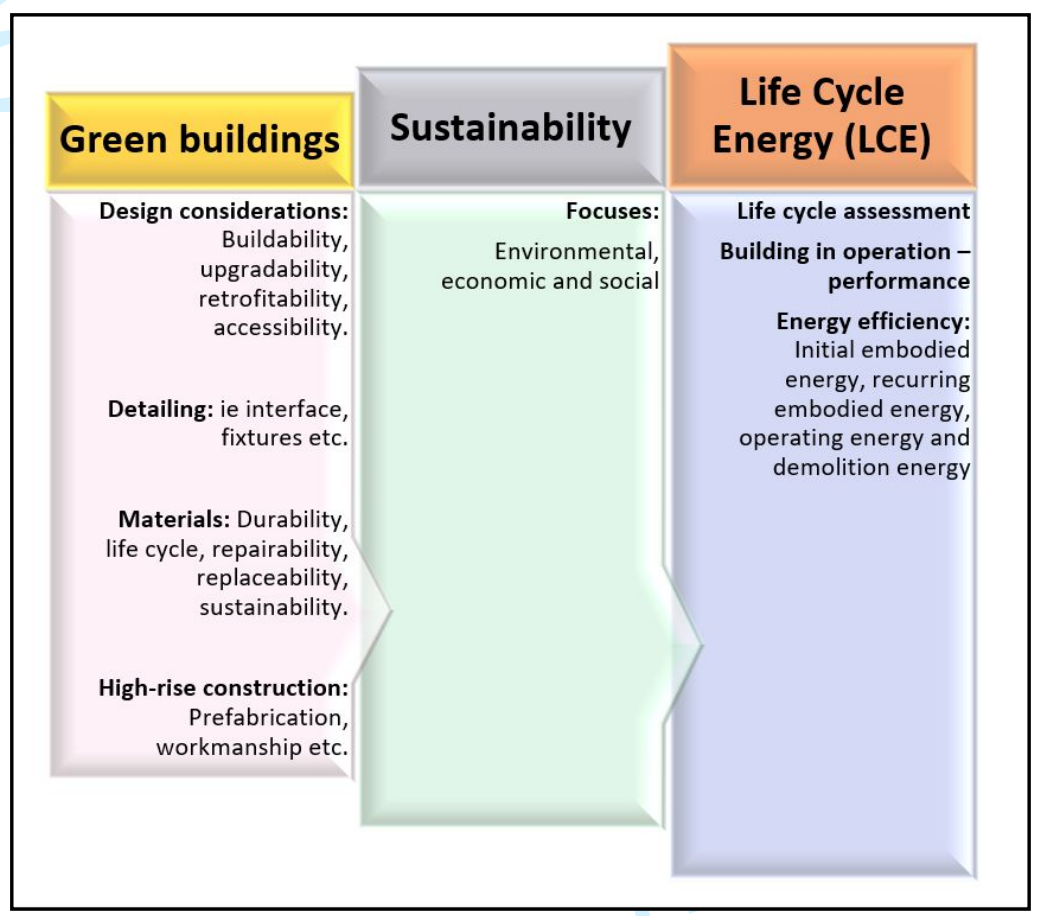

Figure 3: Green building's implications for high-rise constructions (source: authors).

As shown in Figure 3, design considerations, detailing, materials along construction processes are the initial building green considerations. Further, when considering green buildings in high-rise construction, sustainability focuses on environmental, economic, and social needs to be carefully contemplated too. This has been particularly highlighted in an article by Malmqvist et al., (2018). Further, they predominantly emphasized the inclusion of LCE as the basis of wide-ranging green building design. This article also follows on from the previous articles in incorporating the importance of the environmental issues and factors of construction through effective LCE strategies. While LCE can be defined as the total energy (project initiation, design, construction, and operational phases) used during the building life cycle; Malmqvist et al., (2018) highlighted its significance in protecting the environment. Accordingly, in determining the knock-on effects of green buildings, LCE will be the central focus for the high-rise construction design implications.

\subsection{Research methodology}

Via using both quantitative and qualitative methods, this research will undertake extensive literature study along with LCE estimation. This approach of the LCE concept is the basis of research methodology. The research methodology that has been implemented within this research can be easily understood in the 
following diagram, depicting the steps and methods taken to be able to collate all research and knowledge into the research paper. The overall research road-map is shown in Figure 4.

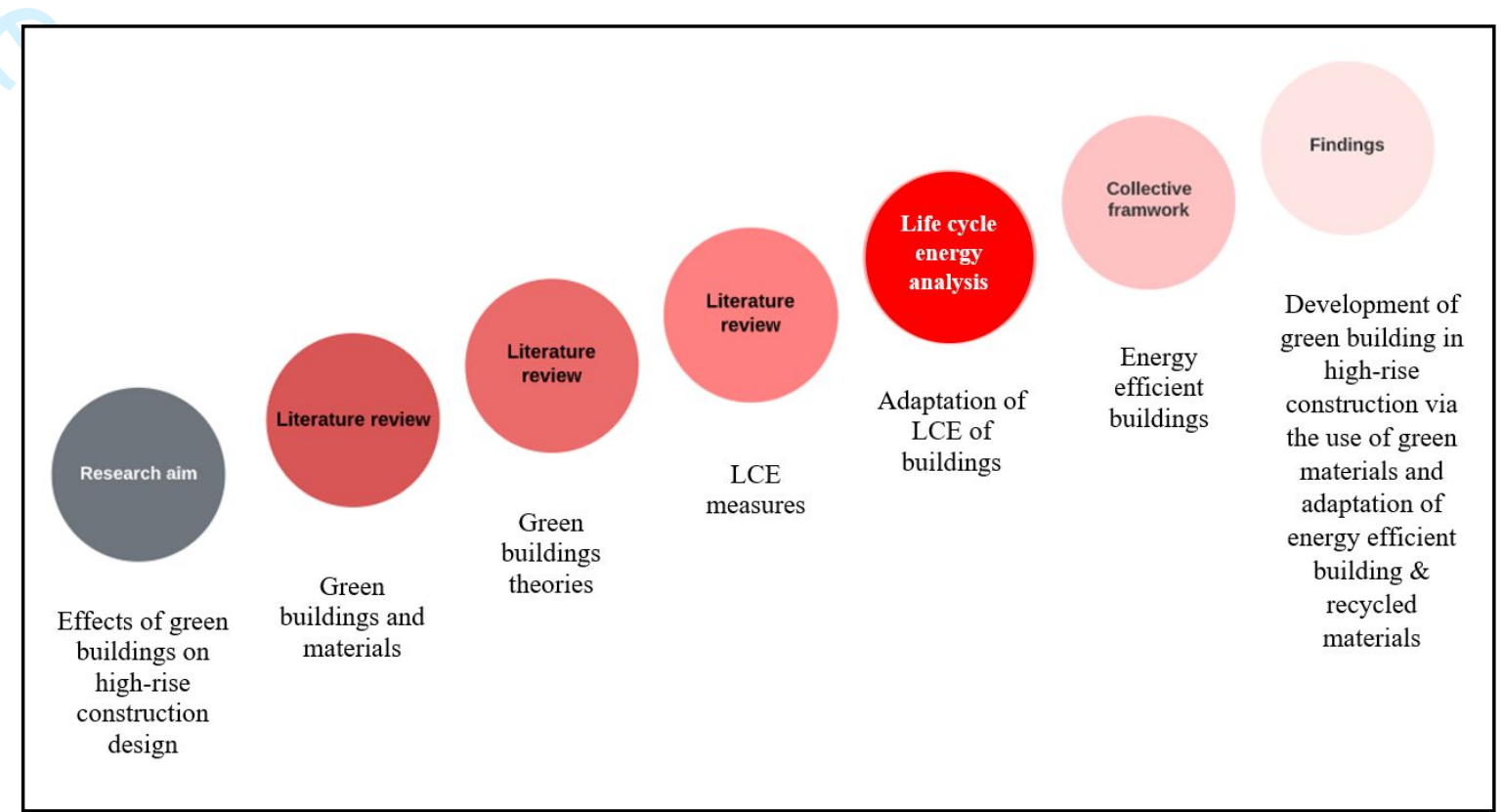

Figure 4: The research road-map (source: authors).

The overall research process followed six specific steps:

- Step 1. Define research problem. As time moves forward it is encouraged that living in an environment surrounding is the best option for the future. In seeing the recent developments throughout all industries of implementing environmentally friendly options it seemed logical to undergo this research and elaborate on the possibilities and opportunities that green building in high-rise construction has to offer. Research is defined as the search for knowledge certainly holds much value throughout this paper as there are constant revelations and discussions relating to the concept of green building and all issues surrounding this topic, the main goal was to define the problem or topic and then create a redefinition for the issue at hand to move forward with the collected research and data.

- Step 2. Review concepts \& theories/ review previous research findings. This step was handled as one of the most crucial points throughout the research. The reason for this is, to commence any other part of the research reviewing the concepts, theories, and any previous research findings must be properly understood so an educated discussion can be formed relating to the topic at hand. The origination of green building, the definition of green building, the recent developments, and limitations surrounding this development, are all topics in which we're required to be extensively researched to be able to develop the basis for the paper.

- Step 3. Formulate hypothesis. As discussed above, to be able to formulate a hypothesis extensive research and development needed to be undertaken to understand what the most appropriate view was to take on this topic. Formulating a hypothesis can only be done once all factors have been laid out and can be absorbed by the researcher. The theory (hypothesis) is developed based on knowledge and own personal views and opinions. In this case, the research presented allowed for an insight into why and how green building is an effective method in high-rise construction, 
how it can be implemented and encouraged, and what is the most appropriate way to incorporate green building without making immense alterations to the standard way of building.

- Step 4. Design research (including sample design). This point of the research stage speaks for itself, in that the research at this point is conducted in favor of the opinion in which the research is directed. It is collecting evidence to support the view of what it is, the research proposal is trying to achieve. In this case, green building in high-rise construction is an achievable and ambitious transition, and the aim is to sway those leaning toward conventional construction in the direction of implementing green construction within their projects, for the many reasons mentioned such as being more efficient in its operation, life cycle, serving to be more costeffective in the long run even if it does not seem that way through the construction phase. These are the types of facts discovered throughout the design research phase that validate the opinions trying to be delivered.

- Step 5. Collect data (Execution)/analyze data. Throughout this stage, there is an opportunity to gain a collection of data that allows an insight into the opposing view being expressed in the paper. This allows for deeper and more comprehensive research as all factors involved with green building in high-rise construction can be evaluated. It is at this point within the research process that rebuttals are formed and a clearer comprehension of the two possible inferences that can be formulated. As discussed more in-depth throughout the research paper the view can either be for green building in high-rise construction which is the direction being pursued or remaining with the conventional build which is much more widely recognized by people who are both involved and not involved in the industry. The analysis of data is a crucial milestone within the research methodology process. The reason for this is, there needs to be an in-depth confirmation that the research being presented is validated, whether that validation is quantitative, qualitative, or through any other method, the individuals on the receiving end of the research require confirmation that the information being presented to them if not primary information, is accurate and correctly researched. This consequently explains the reason why there are many steps involved in the collection of data and analysis, before the commencement of writing the actual research paper.

- Step 6. Interpret and report. The final stage of interpreting the data that has been collected in the previous steps and reporting on the facts that have been presented and researched. Organize the data that has been collated and structure it into a research paper where all views are precisely presented in a relevant arrangement. The objective of the paper is to gain familiarity and achieve new insights into the study through this structure.

In this paper, green building in high-rise construction projects is introduced with facts and definitions into what it is, and all-important factors that need to be understood. Following this, the view that is to be expressed throughout the paper is delivered with supporting facts and reasons as to why this view and opinion has been formed to engage the audience. Next is the combination of all research and data that has been collected whether it be in favor of green building in high-rise construction or against, which will discuss the factors surrounding conventional and standard builds in high-rise construction. 


\subsection{Research approaches/methods}

The secondary data collected for this research will be mainly through narrative extraction by identifying and selecting relevant articles found via reliable scholarly databases and indices. Further, a great deal of the secondary information used will come from familiar industry representatives of construction companies who are familiar with the issues surrounding the green building in high-rise construction. By allowing the research to include information gathered from those who are surrounded by the issue every day allows for a more realistic view to be offered on the topic.

The data collected for this research were analyzed in the form of a table comparing data from standard conventional high-rise buildings, to green buildings. This comparison of the data in a table format provided the opportunity to depict the differences and allow the intended audience of this research to come to their conclusions based on the data and information presented.

\subsection{Selection of research approach/method}

The reason for which the research was conducted in this manner was due to the structure of each step. The fact that each step was clearly defined and dedicated to exploring green building in every aspect whether discussing materials, time scales, cost reductions, or expenses, was all able to be researched more thoroughly whilst proceeding further into the process. as discussed before this in-depth research is important as it is vital for all points raised to be accurately validated and supported by scholarly sources and that is part of the reason why this research approach was chosen, as the opportunity to allow for validation and clarity was able to be completed all before the commencement of writing the report which eliminated any chance of confusion with facts and data collected. When identifying a quality research paper some of the characteristics that will be noticeable will be a formal system implemented, logic will be incorporated into the text, facts, and data that is presented will be empirical and most importantly reputable. In saying this it is believed that the specific research approach selected for this paper accurately allows for these items to be displayed. The LCE analysis of buildings is central for this research. Accordingly, such analysis is undertaken from the initiation, design, construction, and operational phases of the project life cycle. Particularly, this framework is examined as the basis of high-rise construction design implications. The next section will discuss this framework.

\subsection{LCE analysis: High-rise construction design implications}

Through the process of research, concerning green building in high-rise construction. It can be concluded that green building is a more recognized form of building in the twenty-first century as opposed to the recognition it gained in previous years, however, the formalities and methods involved are still foreign to a wide range of builders and developers. Certain methods can be adopted in planning and development stages that can measure the energy consumption, whether it be embodied, operating, demolition, or life cycle energy. This is important as the whole point surrounding the introduction of green building in highrise construction is to allow for a positive effect on the environment, not only during the construction phase but as the building is in operation. These energy level equations will be able to help determine the amount of energy that is in consumption through the life cycle of the building, the aim is to reduce these energy levels, which is commonly achieved through building green. 


\subsection{Results}

The results found when researching the facts about the green building were most commonly surrounded by ways of implementing green building in different ways. The first method of implementation was through client/builder recognition of the advantages involved. By offering knowledge to those in the position to make the change is the most important aspect so having these methods readily available makes all the difference. The information that would need to be communicated is, as discussed above the advantages and negatives and how they balance each other out when put into practice, the different methods of implementing a green building, such as materials and design, and lastly the exact effect and method of determining the energy consumption of the building operation, demolition, and building life cycle. This is imperative information as it can depict to the builder or client just how much a conventional building affects the environment, and just how much a green building can not only monetarily assist the building phase, but how its construction and operation can positively affect the environment.

As explained in a book by Anderzhon et al., (2012) buildings demand energy in their life cycle right from the demolition phase to the construction phase, therefore by using specific energy consumption equations, you can identify phases of construction or demolition in which consume the most energy and from there determine where it is possible to reduce this energy. $30-40 \%$ of primary energy is contributed to the life cycle of buildings, they are then held responsible for up to $50 \%$ of the greenhouse gasses that are emitted into the environment every day.

Consequently, this provides a basis for why there is such stressed importance on achieving sustainable development within society as the effect on the environment is becoming more and more recognized and damaging. By implementing green and sustainable construction for high-rise buildings there is an evident low environmental impact and high economic and social gains that should be more publicized to those of the construction industry as an incentive to incorporate this type of building into their work. As mentioned above Ravi Prakash (2010), in his energy and buildings article explains the equations that can assist in determining the involved energy consumption, which is explained more in-depth below. Embodied Energy is the energy that is consumed during the phase of manufacturing. It is the content involved in all installations in the building, and the energy that is incurred at the erection and construction stage of the building.

The energy content of materials refers to the energy consumed to acquire raw materials through excavation, manufacturing, and transport to the site. Embodied energy can be broken down into two components, Initial Embodied Energy and Recurring Embodied Energy - which are explained below.

(1) Initial Embodied Energy ( $\mathrm{EE}_{\mathrm{i}}$ ): Which is the energy incurred at the time of initial construction of the building. This can be expressed in the equation:

$$
E E_{i}=\sum m_{i} M_{i}+E_{c}
$$

EEi consists of a calculation of the quality of building materials $\left(\mathrm{m}_{\mathrm{i}}\right)$, the energy content of materials per unit $\left(\mathrm{M}_{\mathrm{i}}\right)$, and the energy that is used on-site to erect the materials and construction of the building. Embodied energy concerning the building materials is based on two well-renowned databases, Hammond 
and Jones (2008) and Beemer and Sobon (2016). It is these databases that are most commonly used to determine the Initial Embodied Energy of materials. Table 1 depicts the embodied energy according to these databases.

Table 1: Embodied energy according to Hammond and Jones (2008) and Beemer and Sobon, (2016).

\begin{tabular}{|l|l|l|}
\hline Embodied Energy [MJ/kg] & A\&W & H\&J \\
\hline Concrete & 1.6 & 1.4 \\
\hline Virgin Steel & 32.0 & 35.3 \\
\hline Recycled Steel & 10.1 & 9.5 \\
\hline
\end{tabular}

It is important to remember that there is always a chance of uncertainty to be experienced in; the number of materials uses; embodied energy of the materials and the source and the content of the materials. Due to the above-mentioned points, it is important to allow for these uncertainties within any calculation of embodied energy and to allow for a deviation of approximately $\pm 10 \%$. According to van Geem (2007), certain methods can be implemented within the production of certain materials that may affect the final result of the embodied energy for a particular building. Certain aspects such as replacing cement with fly ash can have a significant effect. For every $1 \%$ of cement that is replaced with Fly ash the embodied energy of concrete is reduced by approximately $0.7 \%$.

In addition to evaluating the embodied energy of each building material that contributes to the construction of a building, the energy that is used to erect and physically construct the building must be considered. RMIT Professor Ralph Horne has documented in his center for design presentation the various calculations for certain materials and the energy of assembly, which is represented in Table 2.

Table 2: The calculations for certain materials and the energy of assembly (Horne, 2008).

\begin{tabular}{|l|c|l|c|}
\hline Material / Assembly & $\begin{array}{c}\text { Embodied Energy } \\
\text { (MJ/M2) }\end{array}$ & Material/ Assembly & $\begin{array}{c}\text { Embodied Energy } \\
\text { (MJ/M2) }\end{array}$ \\
\hline Dried Softwood & 3.4 & Imported Granite & 13.9 \\
\hline Dried Hardwood & 2 & $\begin{array}{l}\text { Local Dimension } \\
\text { Granite }\end{array}$ & 5.9 \\
\hline $\begin{array}{l}\text { Air Dried Sawn } \\
\text { Hardwood }\end{array}$ & 0.5 & Gypsum Plaster & 2.9 \\
\hline Hardboard & 24.2 & Plasterboard & 4.4 \\
\hline Particleboard & 8 & Fiber Cement & 4.8 \\
\hline MDF & 11.3 & Cement & 5.6 \\
\hline Plywood & 10.4 & Insitu Concrete & 1.9 \\
\hline $\begin{array}{l}\text { Glue--Laminated } \\
\text { Timber }\end{array}$ & 11 & $\begin{array}{l}\text { Precast Steam Cured } \\
\text { Concrete }\end{array}$ & 2 \\
\hline $\begin{array}{l}\text { Laminated Veneer } \\
\text { Lumber }\end{array}$ & $\begin{array}{l}\text { Precast Tilt up } \\
\text { Concrete }\end{array}$ & 1.9 \\
\hline
\end{tabular}




\begin{tabular}{|l|c|l|c|}
\hline Plastics-General & 90 & Clay Bricks & 2.5 \\
\hline PVC & 80 & Concrete Blocks & 1.5 \\
\hline Synthetic Rubber & 110 & AAC & 3.6 \\
\hline Acrylic Paint & 61.5 & Glass & 12.7 \\
\hline Stabilized Earth & 0.7 & Aluminum & 170 \\
\hline Galvanized Steel & 38 & Copper & 100 \\
\hline
\end{tabular}

As already noted, the second embodied energy is the Recurring Embodied Energy, which is explained below.

(2) Recurring Embodied Energy $\left(\mathrm{EE}_{\mathrm{r}}\right)$ : Refers to the materials that are being used in construction that have a life span of less than that of the building. As a result of this these materials are replaced in order to rehabilitate the building. In addition to this the building will require some annual maintenance and thus presents the $\mathrm{EE}_{\mathrm{r}}$, which needs to be accounted for during the life of the buildings. The $\mathrm{EE}_{\mathrm{r}}$ is within the material used to rehabilitate and maintain this is expressed through the following equation:

$$
E E_{r}=\sum m_{i} M_{i}\left[\left(\frac{L_{b}}{L_{m_{i}}}\right)-1\right]
$$

Similar to the $\mathrm{EE}_{\mathrm{i}}$ equation, the $\mathrm{EE}_{\mathrm{r}}$ consists of including the calculation for the quality of building materials and energy content of each unit. In addition to these calculations, the recurring energy also requires a calculation for both the life span of the building and the included materials. For the additional calculations to be completed a churn rate is chosen. This churn rate is defined as the number of times the materials are required to be replaced throughout the lifetime of the building. These rates are based purely on experience and detailed research which can accurately reflect the likely life of the materials used and the requirements of building maintenance.

The $\mathrm{EE}_{\mathrm{r}}$ varies greatly between every building. This energy is directly connected to the life of the building as discussed above, therefore if the building was to use more durable materials in the initial stages of construction and regular maintenance is allowed for then the building has a larger chance of survival. Cole and Kernan 1996 have created Figure 5 assuming the life span of 100 years. This figure offers a comparison between $\mathrm{EE}_{\mathrm{i}}$ and $\mathrm{EE}_{\mathrm{r}}$ for a standard wood structure office building. 


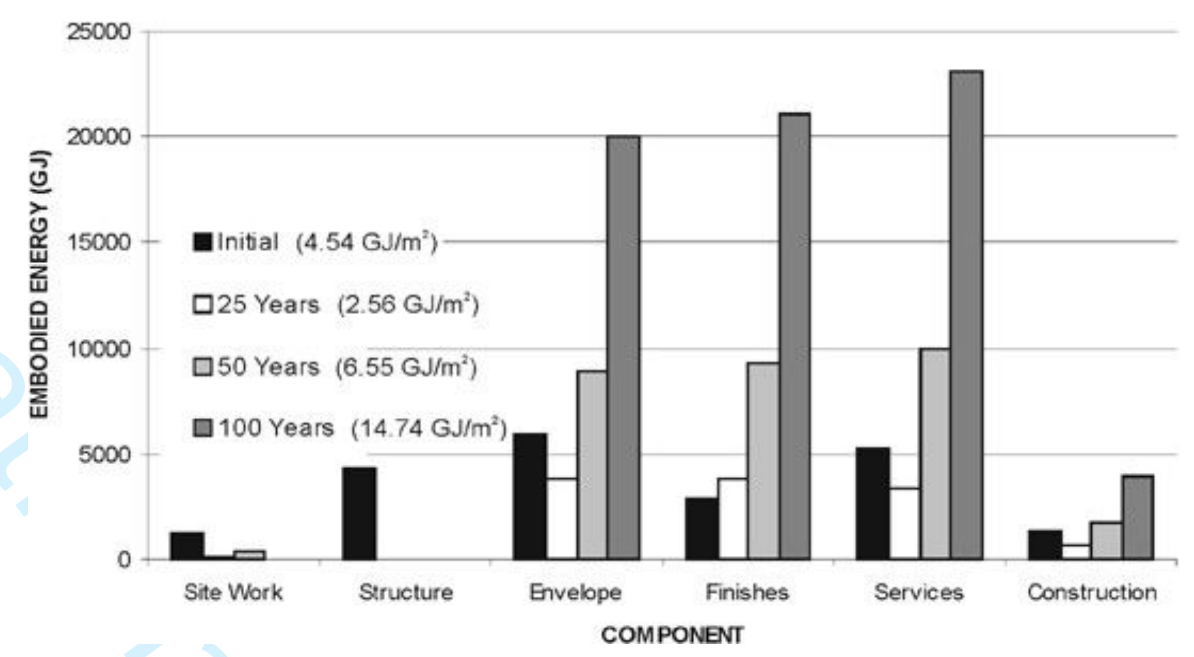

Figure 5: Comparison between $\mathrm{EE}_{\mathrm{i}}$ and $\mathrm{EE}_{\mathrm{r}}$ for a standard wood structure office building (Cole and Kernan, 1996).

The $\mathrm{EE}_{\mathrm{r}}$ calculations are encouraged to be done by highly experienced individuals within the industry as it becomes increasingly difficult over time to predict including factors such as the non-renewable energy contents of replacements materials, components, or systems. As time moves forward it is becoming more acknowledged the embodied energy is a representation of one of many measures and should not become the sole system of selection. A large portion of recurring embodied energy is to do with the type of materials used, and the energy sources that contribute to the making of the building materials and products. Other sources of energy that can be measured and in turn reduced to make for more efficient construction are, Operating Energy, and estimated as per below:

Operating Energy (OE): The energy that is concerned with maintaining comfort levels and conditions in the day-to-day running of the buildings. It is the energy level for HVAC, water, lighting, and appliance operation. Depending on the level of comfort required within a building the operating energy will vary immensely. The operating energy within the life span of a building is expressed as:

$$
O E=E_{O A} L_{b}
$$

The OE calculates the Annual Operating energy $\left(\mathrm{E}_{\mathrm{OA}}\right)$ by the life span of the building $\left(\mathrm{L}_{\mathrm{b}}\right)$. This is due to the fact that operating energy has to do with the energy that is consumed with the everyday running of the building from elements such as, heating, cooling, ventilation, lighting equipment and appliance. As discussed above the climatic conditions of the building has a great significance on the level of energy consumed during the operation of a building. Figure 6 needs to be read in conjunction with Figure 5 by Cole and Kernan representing recurring energy. This graph depicts an estimated building life of 50 years and demonstrates the possible operating energy to be consumed throughout the life of the building. As per Figure 6, the graph showed the operating energy represents around $85 \%$ of the total energy that is consumed at the end of the 50 year cycle of the building. The high-rise office building that is being studied within this case study is an average steel and concrete structure. 


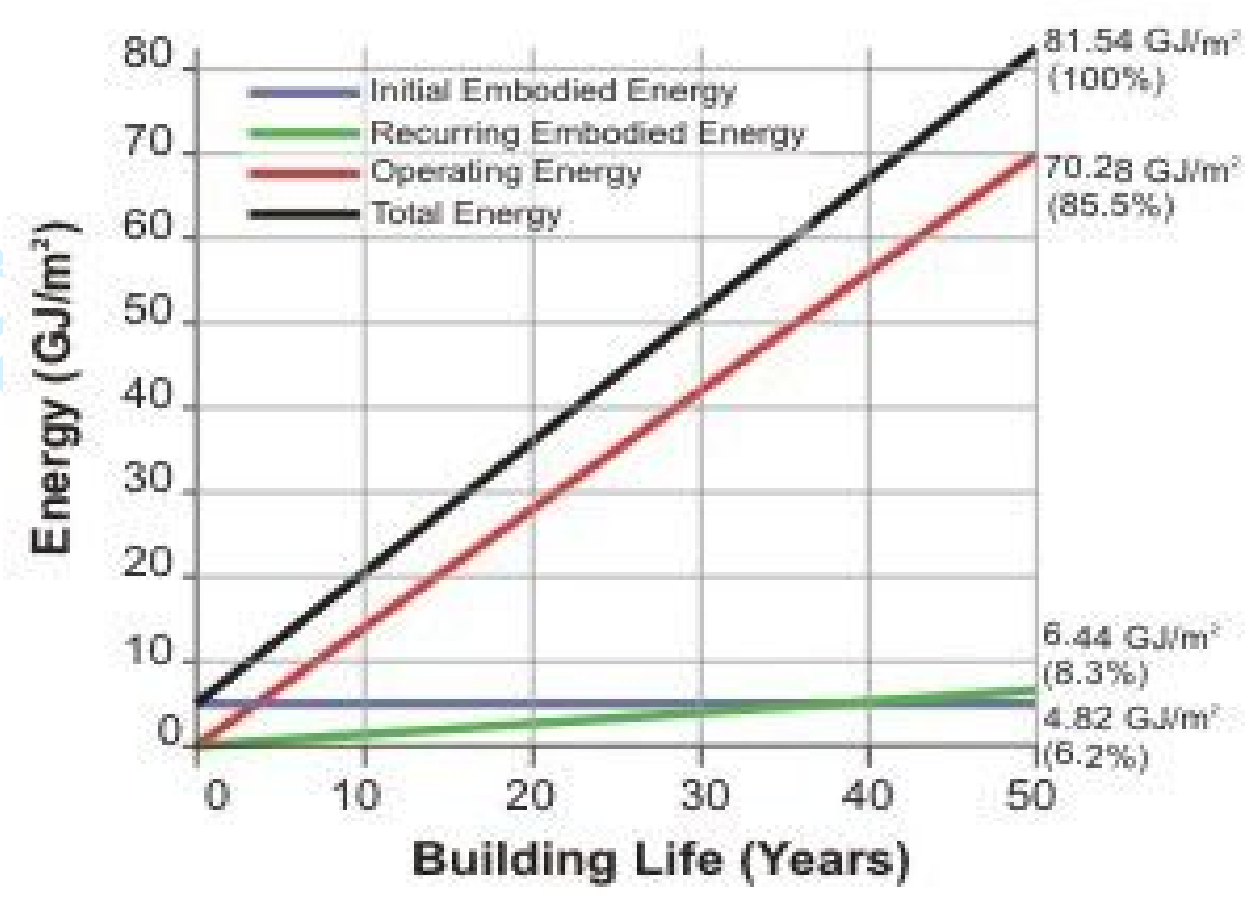

Figure 6: The overall operating energy of the 50-year cycle of the building (source: authors).

Figure 6 is the output of the overall operating energy, which also includes the total energy. The total energy will also consider any other energy used such as Demolition Energy. This energy is calculated as per below:

Demolition Energy (DE): When a building has come to the end of its life, demolition of this building is required. It is not only the demolition of the building that consumes energy it is also transporting these waste materials to landfill sites or recycling plants that consume energy also. This is the energy that is defined as demolition energy and it is expressed in the following equation:

$$
D E=E_{D}+E_{r}
$$

The actual process of demolition and transportation of these demolished materials does not account for much of the overall energy consumption of a building. The transportation energy is calculated at $1 \%$ of the total energy requirement for the building. The energy consumed for the demolition is considered a primary energy source. Finally, the LCE then is calculated as per below:

LCE: The sum of all energies that have been incurred throughout the life cycle of the building. This is expressed as:

$$
L C E=E E_{i}+E E_{r}+O E+D E
$$

After performing assessments on all of the above energy contributions within a building, the LCE can be determined. With the addition of the $\mathrm{EE}_{\mathrm{i}}, \mathrm{EE}_{\mathrm{r}}, \mathrm{OE}$, and $\mathrm{DE}$, the LCE can be clearly defined. Further, to offer clarity into the calculation methods of the LCE of a building or individual building material the following calculations have been completed using the previous figures as examples. As it can be noticed, the level of involvement required when calculating the LCE is complex and multilayered, but necessary. 
This includes the ability to perform specific and comprehensive calculations which in turn can further assist with a more efficient design for high-rise buildings. As a result, an increased understanding of the current status of green buildings within the construction industry is paramount. This understanding leads to a better insight into the contributing factors to green building in high-rise construction and the construction industry in general.

\subsection{Conclusion and recommendations}

The aims and objectives of this research were to establish whether or not the transition into the green building in high-rise construction is practical. This research, therefore, intended to create a better understanding and grasp of the concepts involved in green building in high-rise construction particularly some of the design implications. Further, comparing the conventional construction vs the green methodology, various design implications were investigated. Moreover, this research touched based on the materials that can be used to allow for a more efficient build and details the exact material in which they are replacing. These materials may be complete replacements, or they may be for the inclusion of recycled materials as opposed to using brand new materials. There is a lot of reservation surrounded using recycled materials in that they may not be as effective visually or structurally, however this research details the effectiveness of the use of recycled materials and what a positive effect it has on energy consumption. There is also an inclusion of a detailed description of materials that can be recycled in construction which offers validation for the points raised. These materials included those such as; concrete, steel, aluminum, and plastic.

By way of defining the ongoing relationship of green materials and sustainable design, various implications for high-rise constructions were discovered, including LCE. To examine such considerations, a 50-year cycle of a building was carried out. The findings of this research showed that the operating energy represents around $85 \%$ of the total energy that is consumed at the end of the 50 -year cycle of the building. Such analysis and findings can lead to better awareness in design adaptation of green buildings, particularly for high-rise construction. Nonetheless, further research is required to include a wider range of materials that can be used as substitutes or replacements to those that are used on a standard build. Moreover, further research into different types of high-rise construction may also assist with better design practices which will be beneficial for practitioners such as design engineers and other related professions.

\section{References}

- Akadiri, O., (2015), "Understanding barriers affecting the selection of sustainable materials in building projects", Journal of Building Engineering, vol. 4, pp. 86-93, Elsevier.

- Alcorn, A., and Wood, P., (1998), "New Zealand Building Materials Embodied Energy Coefficients Database Volume II - Coefficients", Centre for Building Performance Research.

- Anderzhon, J., Hughes, D., Judd, S. and Wijnties, M. (2012), "Design for Aging: International Case Studies of Building and Program", Wiley, pp 188-192.

- Arığlu, A., Mahmure, Ö., Dhavale, D., Sarkis, J. (2017), "Greenhouse gas emissions in the construction industry: An analysis and evaluation of a concrete supply chain", Journal of Cleaner Production, vol.167, pp 1195-1207.

- Armstrong, R., (2015), "Embodied intelligence: changing expectations in building performance", Intelligent buildings international, vol 8: issue 1, pp 4-23. 
- Arora, S. (2015), "Recycled Aggregates: A Sustainable Solution of Construction and Demolished Waste", Journal of Mechanical and Civil Engineering, pp 58-63.

- Beemer, W. and Sobon, J.,(2016), "Learn to Timber Frame: Craftsmanship, Simplicity, Timeless Beauty", pp 129-131.

- BHP House --- 140 Williams street 2014, <https://en.wikipedia.org/wiki/140_William_Street>

- Bovea, D., and Powell, C. (2016), "Developments in life cycle assessment applied to evaluate the environmental performance of construction and demolition wastes", Waste Management 50: 151172.

- Braga, M., Silvestre, D., de Brito, J. (2017), "Compared environmental and economic impact from cradle to gate of concrete with natural and recycled coarse aggregates", Journal of Cleaner Production 162: 529-543.

- Charalambides, A., Maxoulis, C., Kyriacou, O., Blakeley, E., and Frances, L. (2019), "The impact of Energy Performance Certificates on building deep energy renovation targets", International journal of Sustainable energy, vol 38, no 1, pp. 1-12.

- Chew, M. and Conejos, S., (2017), "Green maintainability design criteria for nanostructured titanium dioxide (TiO2) façade coatings", International Journal of Building Pathology and Adaptation, vol. 35 No. 2, pp 139-158.

- Chew, M.Y.L. (2016), "Maintainability of Facilities: Green FM building Professionals", World scientific publication, Singapore, pp. 473-537.

- Chew, M.Y.L., Conejos, S. and Asmone, A.S. (2017), "Developing a research framework for the green maintainability of buildings", Facilities, vol. 35, no. 1/2, pp. 39-63.

- Chew, M.Y.L., Conejos, S. and Law, J.S.L. (2017), "Green maintainability design criteria for nanostructured titanium dioxide (TiO2) façade coatings", International Journal of Building Pathology and Adaptation, vol. 35, no. 2, pp. 139-158.

- Chua, L., Zubbir, B., Ali, S. and Au-Yong, P. (2018), "Maintenance of high-rise residential buildings", International Journal of Building Pathology and Adaptation", Vol. 36 No. 2, pp. 137151.

- Cidell, J. (2009), "Building green: The Emerging Geography of LEED.. Certified Buildings and Professionals", vol 61, no.2, pp. 197-200.

- Climate Policy Initiative (CPI), (2017), "Lessons and Innovations to Spur Green Investment in Developing Countries", $\quad$ http://newclimateeconomy.report/workingpapers/wpcontent/uploads/sites/5/2017/04/Lessons-and-Innovations-to-Spur-Green-Investment-inDeveloping-Countries-1.pdf; Viewed 4 July 2020.

- Cole, R.J. and Kernan, P.C. (1996), "Life-..Cycle Energy Use in Office Buildings”, Building and Environment, vol. 31, no. 4, pp 307-317.

- Comparing the Environmental Effects of Building Systems, (1997), "Wood the Renewable Resource Case Study", no. 4, Canadian Wood Council, Ottawa.

- Conejos, S., Chew, M.Y.L. and Azril, F.H.B. (2019), "Green maintainability assessment of highrise vertical greenery systems", Facilities, Vol. 37 No. 13/14, pp. 1008-1047.

- Criteria and Indicators of Sustainable Forest Management in Canada (1997), Canadian Forest Service, Natural Resources Canada, Ottawa.

- De Luca, A., Chen, L. and Gharehbaghi, K. (2021), "Sustainable utilization of recycled aggregates: robust construction and demolition waste reduction strategies", International Journal of Building 
Pathology and Adaptation, in press.

- Densley, D, Davison, T (2012), "Developing an LCA methodology to account for the environmental benefits of design for deconstruction", Building and Environment, vol. 57, pp 387395.

- Dimitriou, S., Kyprianou, I., Papanicolas, C., and Serghides, D., (2020), “A new approach in the refurbishment of the office buildings - from standard to alternative nearly zero energy buildings", International journal of Sustainable energy, vol 39, no 8, 761-778

- Eckelman, M, Brown, C, Troup, L, Wang, L, Webster, M, Hajjar, J (2018), "Life cycle energy and environmental benefits of novel design-for-deconstruction structural systems in steel buildings", Building and Environment, vol.143, pp 421.

- Enshassi, A., Ayash, A. and Mohamed, S. (2018), "Key barriers to the implementation of energymanagement strategies in building construction projects", International Journal of Building Pathology and Adaptation, vol. 36, no. 1, pp 15-40.

- Eriksson, P., Milić, V. and Brostrom, T. (2019), "Balancing preservation and energy efficiency in building stocks", International Journal of Building Pathology and Adaptation, vol. 38, no. 2, pp 356-373.

- Estanqueiro, B, Dinis Silvestre, J, de Brito, J, et al. (2018), "Environmental life cycle assessment of coarse natural and recycled aggregates for concrete", European Journal of Environmental and Civil Engineering 22, pp 429-449.

- Gharehbaghi, K. (2015), "Advancements in concrete technology in Australia: geo-polymer concrete", International Journal of Constructed Environment, vol. 7, no. 1, pp 19-29.

- Gharehbaghi, K. (2017), "Modular high-rise construction as an alternative building system", International Journal of the Constructed Environment, vol. 8, no. 3, pp 15-25.

- Gharehbaghi, K. and Chenery, R. (2017), "Fiber reinforced concrete (FRC) for high rise construction: case studies", Materials Science and Engineering, vol. 272, pp 223-229.

- Gharehbaghi, K. and Rahmani, F. (2018), "Practicalities and developments of high-rise composite structures: case studies”, Materials and Technologies in Engineering, pp 153-159.

- Gharehbaghi, K., Georgy, M. and Rahmani, F. (2018), "Composite high-rise structures: structural health monitoring (SHM) and case studies", Materials and Technologies in Engineering, pp 146152.

- Gharehbaghi, K., Rahmani, F. and Paterno, D. (2020a), "Adaptability of materials in green buildings: Australian case studies and review", IOP Conference Series: Materials Science and Engineering, vol. 829, 012006.

- Gharehbaghi, K., Rahmani, F. and Paterno, D. (2020b), "Sustainable concrete in transportation infrastructure: Australian case studies”, IOP Conference Series: Materials Science and Engineering, vol. 829, 012001.

- Gharehbaghi, K., Tee, K., Gharehbaghi, S., (2021a), "Review of Geopolymer Concrete: A Structural Integrity Evaluation", International Journal of Forensic Engineering, vol. 5, issue 1, pp. 59-71.

- Gharehbaghi, K., Georgy, M., Robson, K.M., Wilkinson, S. and Farnes, K., (2021b), "Versatility in sustainable building design (SBD) practices: an empirical study", International Journal of Building Pathology and Adaptation, in press. 
- Guerra, B, Bakchan, A, Leite, F, Faust, K (2019), "BIM-based automated construction waste estimation algorithms: The case of concrete and drywall waste streams", Waste Management, vol. 87, pp 825-832.

- Hadavand, B, Imaninasab, R (2019), "Assessing the influence of construction and demolition waste materials on workability and mechanical properties of concrete using statistical analysis", Innovative Infrastructure Solutions, vol. 4, no. 1.

- Hahladakis, J., Purnell, P., Aljabri, H., (2020), "Assessing the role and use of recycled aggregates in the sustainable management of construction and demolition waste via a mini-review and a case study", Waste management and research, vol 38, issue 4.

- Hirokazu S., Hisashi T., Ryuji M. and Yoshikuni Y., (2005), “An advanced concrete recycling technology and its applicability assessment through input-output analysis", Journal of advanced technology - Japan concrete institute, vol. 3 no. 1, pp 53-67.

- Hirvonen, J., Jokisalo , J., Heljo, J., and Kosonena, R. (2019), "Towards the EU emissions targets of 2050: optimal energy renovation measures of Finnish apartment buildings", International journal of Sustainable energy, vol 38, no 7, pp. 649-672.

- Horne R. (2008), "Embodied Energy in Buildings. A review”, RMIT University.

- Hossain, M., Poon, C., Lo, I., et al. (2016), "Comparative environmental evaluation of aggregate production from recycled waste materials and virgin sources by LCA", Resources, Conservation and Recycling 109, pp 67-77.

- Huijun, W., Diao, Z. and Fan, K. (2020), "Study on durability of non-dispersible concrete in seawater environment", International Journal of Structural Integrity, Vol. 11 No. 3, pp. 443-452

- Iacovidou, E., Millward-Hopkins, J., Busch, J., et al. (2017), "A pathway to circular economy: Developing a conceptual framework for complex value assessment of resources recovered from waste", Journal of Cleaner Production 168, pp 1279-1288.

- Iacovidou, E., Purnell, P. (2016), "Mining the physical infrastructure: Opportunities, barriers and interventions in promoting structural components reuse", Science of The Total Environment 557558, pp 791-807.

- Ilhan, B., and Yaman, H. (2016), "Green building assessment tool (GBAT) for integrated BIMbased design decisions", Automation in Construction, vol. 70, pp 26-37.

- Jaillon, L. \& Poon, S. (2008), "Sustainable construction aspects of using prefabrication in dense urban environment: a Hong Kong case study", Construction Management and Economics, vol. 26, no.9, pp 953 $\cdots 966$.

- Jones, C. (2019), "Wooden buildings reach new heights”, Materials World magazine, 270219.

- Kheradmand, M., Jahangiri, K., Sohrabizadeh, S., Safarpour, H. and Khani Jazani, R. (2019), "Physical seismic vulnerability assessment of neighborhood emphasizing on critical land uses", International Journal of Structural Integrity, Vol. 10 No. 2, pp. 176-187

- Krueger, K., Stoker, A. and Gaustad, G. (2019), "“Alternative" materials in the green building and construction sector: Examples, barriers, and environmental analysis", Smart and Sustainable Built Environment, vol. 8, no. 4, pp 270-291.

- Kubba, S. (2016), Handbook of Green Building Design and Construction - LEED, BREEAM, and Green Globes, 2nd Edition, Butterworth-Heinemann, pages 1064. 
- Kumari., T., Kulathunga, U., Hewavitharana, T., and Madusanka, N., (2020), "Embodied carbon reduction strategies for high-rise buildings in Sri Lanka", International journal of construction management, in press.

- LEED stands for green building leadership, (2015), U.S. Green Building Council, Viewed 5 July 2019, <http://www.usgbc.org/leed>

- Lieblang, P. (2014), "Sustainable Construction with Concrete", Modern Concrete Construction Manual, Structural Design, Material Properties, Sustainability, vol. 1, no. 1, pp 116-129.

- Lockrey, S., Verghese, K., Crossin, E. and Nguyen, H. (2018), "Concrete recycling life cycle flows and performance from construction and demolition waste in Hanoi", Journal of Cleaner Production, vol. 179, pp 593-604.

- Lotfy, A., and Al-Fayez, M. (2015), "Performance evaluation of structural concrete using controlled quality coarse and fine recycled concrete aggregate", Cement and Concrete Composites 61, pp 3643.

- Lukman, A., AkanbiacLukumon, O., Olugbenga O., Akinadea, AjayiaJuan, A., Davila, M., Hakeem D., Owolabia, A. (2019), "Disassembly and deconstruction analytics system (D-DAS) for construction in a circular economy", Journal of Cleaner Production, vol. 223, pp 386-396.

- Maduabuchukwu C., Nwakaire, C., Poh Yap, S., Chuen Onn, C, Wah Yuen, C. \& Adebayo Ibrahim, H. (2020), "Utilisation of recycled concrete aggregates for sustainable highway pavement applications; a review", Construction and Building Materials, vol. 235.

- Malmqvist, T., Nehasilova, M., Moncaster, A., Birgisdottir, H., Rasmussen, N., Wilberg, A., Potting, J. (2018), "Design and Construction strategies for reducing embodied impacts for building - case study analysis”, Energy and Buildings, vol.166, no.1, pp 35-47.

- Mirrahimi, S., Mohamed, M., Haw, L., Ibrahim, N., Yusoff, W., and Aflaki, A., (2016), "The effect of building envelope on the thermal comfort and energy saving for high-rise buildings in hot-humid climate", Renewable and Sustainable Energy Reviews, Volume 53, pp 1508-1519.

- Mohammed, L., Mosleh, M., and Saeed, A., (2015), "The Effect of Some Admixtures on Structural Behavior of Self-Compacting Recycled Aggregates", Master of science in civil engineering, AlMustansiriya university, College of Engineering, department of civil engineering, pp 110-120.

- Ollila, A.V.E. (2012), "The roles of greenhouse gases in global warming", Energy and Environment, vol. 23, no. 5, pp. 781-799.

- Pacheco-Torgal, F., Cabeza, L., Labrincha, J., and de Magalhaes, A., (2013), "Eco-efficient Construction and Building Materials: Life Cycle Assessment (LCA), Eco-Labelling and Case Studies", Elsevier, pp 433-441.

- Pacheco-Torgal, F., Jalali, S. (2011), "Toxicity of building materials: a key issue in sustainable construction", International Journal of Sustainable Engineering, vol. 4, no. 3, pp 281-287.

- Peng, Z., Deng, W. and Hong, Y. (2019), "Materials consumption, indoor thermal comfort and associated energy flows of urban residential buildings: Case studies from the cold climate zone of China", International Journal of Building Pathology and Adaptation, vol. 37, no. 5, pp 579-596.

- Raji, B., Tenpierik, M., and Dobbelsteen, A., (2015), "An assessment of energy-saving solutions for the envelope design of high-rise buildings in temperate climates: A case study in the Netherlands", Energy and Buildings, Volume 124, pp 210-221

- Ravi Prakash, (2010), "Life Cycle Energy”, Energy and Buildings, Viewed 9 February 2020. 
- $\quad$ RMIT Capital Works http://www.rmit.edu.au/capitalworks/city/slab, last viewed $11^{\text {th }}$ March, 2020.

- RMIT University, <http://www.rmit.edu.au/maps/melbourne--city-.. campus/building...80/> last viewed December $3^{\text {rd }}$ September, 2020.

- Sim, D. (2019), "Soft City: Building Density for Everyday Life”, Island Press, pp 234-241.

- Singh, M., Ohji, T. \&Asthana, R., (2015), "Progress and Prospects", Green and Sustainable Manufacturing of Advanced Materials, 1 edition, pp 3-10, Elsevier.

- Thormark, C. (2002), "A low energy building in a life cycle—its embodied energy, energy need for operation and recycling potential" building and environment, vol. 37, issue 4, pp 429-435.

- U.S. Green Building Council, (2000), "Leadership in Energy and Environmental Design”, vol 2.0, Viewed 9 September 2020.

- United Nations Environment Program (2018), "Global Material Flows and Resource Productivity", $<$ file://C:/Users/chased/Downloads/global_material_flows_full_report_english.pdf $>$. Viewed 28 May 2019).

- Xua, J., Fleiterb, T., Eichhammerb, W., Fana, Y. (2012), "Energy consumption and CO2 emissions in China's cement industry: A perspective from LMDI decomposition analysis", vol. 50, pp 821832.

- Yan, X., Ren, X. \& Li, J. (2017), "Compressive behaviour of concrete under different loading rates: Experimental analysis", Life-Cycle of Engineering Systems: Emphasis on Sustainable Civil Infrastructure - 5th International Symposium on Life-Cycle Engineering, IALCCE 2016, pp. 1729.

- Yang, L. and Li, Y, (2008), “Cooling Load Reduction by using thermal mass and night ventilation”, Energy and Buildings, (Viewed 4 March 2021).

- Zhang, C. \& Canning, L. (2011), "Application of non-conventional materials in construction", Proceedings of Institution of Civil Engineers: Construction Materials, vol. 164, no. 4, pp 165-172.

- Zou, P., Zhang, G., Wang, J. (2007), "Understanding the key risks on construction sites in China”, International Journal of Project Management, vol 25, no.1, pp 601-614. 